\title{
On the Value of Patents in Lean IP Management
}

\author{
Oliver Baldus ${ }^{1}$, Pierre Dübon ${ }^{2}$, Michael Barth ${ }^{3}$ \\ ${ }^{1}$ Schwarz and Baldus LLP, Munich, Germany \\ ${ }^{2}$ Munich, Germany \\ ${ }^{3}$ Eder Schieschke \& Partner mbB, Munich, Germany \\ Email: `baldus@sb-ip.de, pierre_duebon@gmx.de, michael.barth@eder-ip.de
}

How to cite this paper: Baldus, O., Dübon, P. and Barth, M. (2018) On the Value of Patents in Lean IP Management. American Journal of Industrial and Business Management, 8, 1113-1122.

https://doi.org/10.4236/ajibm.2018.85077

Received: April 18, 2018

Accepted: May 6, 2018

Published: May 9, 2018

Copyright $\odot 2018$ by authors and Scientific Research Publishing Inc. This work is licensed under the Creative Commons Attribution International License (CC BY 4.0).

http://creativecommons.org/licenses/by/4.0/

\begin{abstract}
This article highlights under which unique conditions value can be assigned to patents by the concept of Lean IP Management. In general, a patent can be regarded as a positive asset when it covers a product having market potential and it can be enforced as a prohibition right effectively. In particular, there exist three core criteria for monetary evaluating patents. The first and most basic criterion relates to the fact that only those patents protecting subject-matter that has market potential can be considered as positive assets. The second and the third criteria stipulate that even if the first criterion is fulfilled, the patent has to be enforceable in reality in order to be seen as a positive asset. In summary waste avoidance not only in general business operations but also in handling of IP rights is the core measure and most efficient tool for sustained growth of the enterprise. By consequently sorting out negative assets by Lean IP Management, the overall value of the patent portfolio is increased and managing of remaining IP rights can be conducted more efficiently.
\end{abstract}

\section{Keywords}

IP Management, Lean IP Management, Monetary Value of Patents, Assessing Inventions, Saving Costs

\section{Introduction}

Lean production by conventional definition is an integrated socio-technical system whose main objective is to eliminate waste by concurrently reducing or minimizing supplier, customer, and internal variability [1]. Conventional lean management or lean production prescribes the elimination of all non-value-adding activities within a system, with "value" being defined as any action or process that a customer would be willing to pay for [2].

The elimination of waste and the optimal allocation of resources are the pri- 
mary goal of "lean" [3]. By adopting a lean strategy, firms can produce more efficiently, economically, and ecologically for their customers, thereby increasing their own profitability and competitiveness.

Basic ideas of lean production can be found already at the turn of the 20th century. However, the term of lean production was coined first time in 1988 by John Krafcik [4]. Afterwards lean production ideas soon became widely known and accepted [5]. Nowadays, the "lean" concept has become well-established in almost all domains of production and management.

However, lean strategies have never been applied to the management of intellectual property rights. It is estimated that currently only $15 \%$ of all patents have relevance to the market and the firm [6]. Further, it is estimated that $90 \%$ of the patent portfolio do not influence or support the business of most companies [7]. Consequently, $85 \%$ to $90 \%$ of all patents can be considered as waste within the meaning of Lean IP Management. Only $30 \%$ of all patents are vaguely believed to be infringed by the corresponding inventors. Actual infringement, however, seems to be much lower, since only in half of these cases at least rudimental steps were taken towards enforcement [8]. This additionally supports the view that only $15 \%$ have relevance to the market or the firm. Thus, in practice current patent portfolios contain many patents that incur dramatic costs without ever generating positive business effects. By sorting out these "bad" patents and patent applications, costs for IP management could be lowered down to $10 \%$. Further savings are possible, if other lean IP measures are additionally conducted.

By transferring the ideas of lean management to the more special concept of Lean IP Management (LIPM) indispensable conditions can be found that determine whether a patent is a positive asset and has a monetary value or if a patent is a negative asset that wastes financial resources of the firm [9]. In agreement to the definition of value in conventional lean management, a patent can be seen as a positive asset having a monetary value or a value-adding patent, if a buyer or a licensee would be willing to pay for it. In contrast, a patent is a negative asset or a value-subtracting patent, when no buyer could be found for it, since granting and maintaining of the patent produce large costs. Average costs for a single patent in a period of 10 years are estimated to an amount of $12.000 €$ [10]. Costs for longer maintaining the patent often exceed this amount by far.

Although already numerous and detailed concepts for evaluating patents exist, they all suffer from the fact that they disregard the central core argument [11] [12]: The value of a patent is a proxy for the economic impact of the subject-matter protected by the patent. However, a mere patent as such has no value. If the protected subject-matter has no value, a patent for this subject-matter has neither value. If the subject-matter can be easily replaced by another simpler product, market relevance of the subject-matter suffers and so the value of the corresponding patent. If there is no buyer willing to buy the protected product, there will be no buyer interested in purchasing the patent for this product. In this case, the value of the patent is negative. Further, the value of a patent is not a static, but a dynamic parameter. As an example, the value of patents relating to 
compact disks (CDs) shrinks, since compact disks decrease in being used by the market.

Willingness to buy can be evaluated from two perspectives. On the one perspective willingness to buy can be judged from the external viewpoint of purchasing a patent from a third party. In this case the company often has made detailed considerations why to buy a patent or license and what monetary amount to pay for. On the other perspective willingness to buy can be judged form the internal viewpoint of selling an own patent based on own internal research and development activities to a third party.

Surprisingly, many firms often hold large number of self-generated patents for which they never would be willing to pay for, if they were purchased from a third party. These are exactly the value-subtracting patents that waste company resources, since they are held due to a too internal and focused view of the own company. Finally, this unbalanced socio-technical misinterpretation between the internal and the external viewpoint leads to the massive company and welfare losses.

The first premises for a patent being a positive asset, thus reads in agreement with the concept of lean management as:

"Only a patent that a buyer would in principle be willing to pay for is a positive asset."

To derive more detailed criteria for determining, whether a patent is a positive asset, it is necessary to consider the legal nature of patents. The nature of the patent is that a granted patent is per definition a prohibition right that excludes third parties from using the invention claimed. To the opposite, this must not be confounded with a right of allowance that gives its owner the right of using the invention against third parties. All patents are mere prohibition rights but no allowance rights. Further, patents do not necessarily constitute monopoly rights for the firm, since often other protected inventions must be used for realizing the final product. The difference between the right to prohibit and the right to allow has severe implications on their monetary value.

Therefore, the second premise reads as:

"A patent is a prohibition right that excludes third parties from using the invention claimed."

By combining both premises the basic principle of Lean IP Management (BP-LIPM) is derived.

"A patent is a positive asset if a potential buyer would be willing to pay for the prohibition right granted by the patent."

This basic principle of Lean IP Management tells us about the criteria a patent must fulfill to have monetary value.

\section{Market Relevance}

Most important criterion for the value of a patent is market relevance of the un- 
derlying protected subject-matter. In general, any potential buyer would buy a monetary asset only if it has the prospect of an expected return on investment that exceeds the purchasing price. In general, any rights as assets can be contributed a monetary value only, if the corresponding right can be executed. For example, a right of preemption has monetary value only if the preemption can be actually enforced. If not, the corresponding right is worthless.

With respect to prohibition rights this means that it is required to be able to execute these rights. This requires two prerequisites. First, of course the prohibition right needs to exist. But secondly, the prohibition right needs to have an addressee. Without this addressee the prohibition right is principally existent, but not enforceable due to a lack of an infringer. In order to have an addressee the subject-matter protected by the patent has to be economically interesting enough to be used by the market. A Patent for subject-matter that is not interesting enough to be used by the market correspond to a prohibition right without someone interested in using the invention. This can be seen as a prohibition right without any kind of a possible future infringer so that the right to prohibit-although principally existent-cannot be effectuated due to a lack of a suitable object [9].

In consequence, a buyer would never be willing to pay for a patent that protects subject-matter that is not used and will never be used by the market. Thus, a positive asset patent protects subject-matter that is already used by the market or at least has a prospect to. The higher the actual or possible market potential of the protected subject-matter, the higher is the value of a patent. In this sense, the value of the patent is a direct proxy of the market potential of the protected invention. If the protected invention has no market potential, the corresponding patent is also worthless. If the market potential of the invention shrinks, for example due to the invention becoming obsolete, the value of the patent drops accordingly.

Criterion I:

"A valuable patent protects subject-matter that has market potential. The higher the market potential of the protected subject-matter, the higher is the value of a patent."

Patents that cover subject-matter without market relevance are negative assets that withdraw financial resources from the firm. These patents cannot generate a positive effect on own business activities.

Although more detailed criteria are discussed for evaluating patents [10] [11], most of these can principally embraced by the concept of the market potential discussed afore. For example, an invention that can easily be replaced by a different technical solution has lower market potential than an invention that cannot be bypassed technically without causing significantly higher costs. In agreement with their market potential a patent for the letter invention has a higher value, than a patent protecting the invention that can be bypassed.

In general, lack of market potential can have various reasons. In case of a 
technical product, it can be too expensive or complex to produce the product in relation to the technical effect achieved with it. A golden anchor might have a beneficial technical effect that justifies granting a patent for it, since it sinks to the ground faster than other anchors. However, golden anchors are too expensive and do not have market potential. In case of a pharmaceutical an official drug approval is required before selling it on the market. As long as the official drug approval is missing, a patent for the pharmaceutical is clearly a negative asset. If in contrast, however, drug approval exists or there is a prospect to, the patent can be a positive asset that represents a value of billions. In addition, there might be other reasons for lack of market potential. A light bulb having a filament made from uranium might eventually produce light more efficiently than one having a filament made from tungsten, since it needs no external energy source. Nevertheless, uranium light bulbs cannot be sold, since they would be harmful to humans if damaged.

Despite from various practical reasons there are often serious and extremely important legal reasons for losing market potential in practice, i.e. patent claims that are too narrow. The more technical features a patent claim involves, the narrower is the scope of the protected product. Highly specialized subject-matter defined by dozens of technical features is extremely likely to have no market potential, since the product can be easily bypassed by simply omitting or technically modifying only one of the technical features. Therefore, it is extremely important in Lean IP Management that patent claims cover only the most essential core of the inventions and all technical features not belonging to this core are omitted. In practice a large number of inventions, however, is over-defined by a number of absolutely nonessential features in patent claims. These patents can be identified very easily as protecting subject-matter suffering from a lack of market potential.

In summary it can be found that the existence of a sound and reliable market potential of the protected subject matter is the most basic key factor for a valuable patent.

\section{The Buyer-Infringer Relationship}

Market potential is not the only key factor, however. It turns out that not all buyers could effectuate their prohibition rights in the same manner and to the same extent [13] [14]. This has to do with the particular IP context given by their mutual IP relationship to a possible infringer of the patent.

A simple example is an equal competitor (equal player) of the firm also having prohibition rights affecting own business. In this case a mutual stand-off position in IP rights arises, in which both parties could theoretically hit the other party with their prohibition rights. However, striking at the other firm is not reasonable for any of the firms, since the other company must retaliate for an optimum tit-for-tat-strategy in terms of game theory [15]. Knowing this fact each firm would refrain from directly using its prohibition rights against the 
equal competitor. In this case, patents can be seen as static walls surrounding own business activities but not as weapons with respect to the competitor [13] [14].

In this situation mutual coexistence and coevolution between the firms is achieved, in which both firms tolerate the other infringing own patents [15]. Although prohibition rights cannot be enforced directly to their full by any of the parties, they act indirectly on the other party in a disciplining manner and cause peaceful cooperation. This also has consequences on their monetary value.

This situation, however, changes dramatically if one party is stronger in striking with IP rights than the other. The larger this mutual imbalance between the firms is, the more directly prohibition rights can be used by the stronger company, since the fear of retaliation decreases. The more the imbalance between the firms rises, the more patents change their character from walls into mighty weapons. If, however, the patent is held by a much weaker company in an IP imbalance, it cannot be enforced due to the likelihood of being subject of strong retaliation measures by the stronger firm.

This implies dramatic effects on the value of patents. While in the first case of equal competitors, prohibition rights act passively to some extent disciplining on the infringer, in the second case of a much stronger company prohibition rights can be enforced aggressively. In the third case of a much weaker company patents cannot be used as prohibition rights. This can be termed as weakness position.

Consequently, the amount of possible prohibition changes in dependence on being affected by retaliation measures. Thus, one and the same patent changes in value the more it belongs to an owner who can actually use it as prohibition right. Weak companies cannot use patents against an infringer who has the capability of massively striking back. In this case the patent is a weak asset, although protecting products having market potential. If, however, the like patent is owned by a strong company that cannot be hit by retaliation measures of the infringer, it is a strong and valuable positive asset. If absolutely no retaliation is possible, the patent can be used as prohibition right to its fullest extent. This is the case when the patent belongs to a non-practicing entity, often called patent troll.

Therefore, not all owners can execute a patent as prohibition right due to a unilateral dependence on the infringer. The more the prohibition right can be executed by a buyer with respect to an infringer, the more positive the patent as an economic asset is. This brings us to the next criterion for patent being a positive asset:

Criterion II:

"A valuable patent belongs to an owner who is capable of enforcing the prohibition right conferred by the patent, since he is not subject to retaliation measures of an infringer." 
Thus, even if the patent covers subject-matter having market potential (criterion $\mathrm{I}$ ), it has to be held by an owner who is not subject to retaliation measures to be able to actually enforce the granted prohibition right.

\section{Law System}

A further requirement for a patent being a positive asset is that the corresponding law system allows efficiently enforcing prohibition rights. Each patent is bound to a particular national law system. Thus, prohibition rights conferred by patents can only be enforced within the corresponding national legal system. However, if a national legal system does not allow efficiently enforcing rights, the value of a patent in this law system decreases accordingly. In this context it has to be considered that legal certainty is provided by the law system, expenses for enforcing protective rights are not immoderate and the law system is not known for favoring certain groups.

It is a common misconception that protective rights can only be obtained in jurisdictions having a functioning legal system. While examination of a patent application can be oriented to foreign examination procedures, for infringement actions always a national court is required. For example, even in European nations, like Italy, infringement procedures often last more than 10 years [16]. This overlong duration of proceedings already prevents an efficient enforcement of prohibition rights. Other developing nations do not even have a reliable court for judging patent matters and perform even worse.

Consequently, even if a patent covers subject matter having market potential (criterion I) and is held by an owner who is not subject to retaliation measures (criterion II), the law system connected with the patent still must allow efficiently enforcing granted prohibition rights for a valuable patent. A patent granted in nations with an inefficient or improper legal system lacks monetary value and is to be considered as negative asset although the first two criteria are fulfilled.

Temporarily, effective law systems can be found for example in Germany, UK, USA, Canada, Japan and Korea [17]. The less the law system allows enforcing prohibition rights, the lower is the value of a corresponding patent. Therefore, the value of a patent depends on the nation in which it is granted. In this legal context the value of the patent again changes with the market potential that is covered by the law system. If a patent is granted in a legal system that affects only a relatively small number of market participants, like for example Switzerland, value of a patent is minor.

In some instances, the law system must be willing to grant patents for specific subject-matter which could concern public good, so that these patents do not become a negative asset. In the year 2013 a seven-year litigation fought by Novartis on patenting their anti-cancer drug Gleevec in India ended with the result that no patent protection for Gleevec could be obtained in India. This decision became the subject of a controversial debate on balancing public good with monopolistic pricing [18]. 


\section{Criterion III:}

"A valuable patent is granted in a law system that allows reliably and efficiently enforcing granted prohibition rights."

Hence, before spending money for filing a patent application in particular nations it is important to carefully investigate, whether the law system of the respective nation allows enforcing patents at all.

\section{Other Criteria}

Further, more technical parameters exist for a patent being a positive asset. As a matter of course, the patent must be legally valid. Patents, which are questionable in having legal validity with respect to the prior art, have as a matter of course lower values.

Additionally, remaining maximum duration of the patent additionally determines its value. Patents that are close to their maximum duration of 20 years are minor in value then younger patents protecting same subject-matter.

\section{Summary}

This article highlights under which clear conditions value can be assigned to patents by the concept of Lean IP Management. In general, a patent can be regarded as a positive asset when it covers a product having market potential and it can be enforced as a prohibition right effectively.

In particular, there exist three core criteria for monetary evaluating patents. The first and most basic criterion relates to the fact that only those patents protecting subject-matter that has market potential can be considered as positive assets. The second and the third criteria stipulate that even if the first criterion is fulfilled, the patent has to be enforceable in reality in order to be seen as a positive asset.

The discussed concept of Lean IP Management for assessing the value of patents constitutes a paradigm change with respect to the past and could change patent world dramatically. Not only worthless patents held by industry could be easily sorted out without impairing business, but also patents given as loan securities to banking institutes should be reassessed according to financial standards in a true and fair view to determine whether they lack sufficient monetary value.

One of the major challenges of Lean IP Management is ascertaining at an early stage of the patenting process, whether an invention complies with the basic principle of Lean IP Management (BP-LIPM) outlined above. Irrational arguments of companies, like for example the fear of inhibiting internal innovation when not patenting every invention or the crestfallen fear of taking wrong decisions should be disregarded to implement an optimum Lean IP strategy [19].

Counting patents in patent pool agreements, where the rights and benefits of the participating companies are dominated by the mere number of their intro- 
duced protective rights and not by their value, contradicts the concept of Lean IP Management completely. This behavior can be seen as a mystic try to estimate the value of a hand in a poker game by mere counting the number of playing cards of the opposite players. Another irrational fear relates to preventing patenting of homemade inventions by a competitor. If it is questionable that these inventions comply with Lean IP Management standards, legal protection by third parties can be easily prevented by generating prior art describing the invention. In this case expensive and non-efficient patent procedures are avoided.

In summary waste avoidance not only in general business operations but also in handling of IP rights is the core measure and most efficient tool for sustained growth of the enterprise. By consequently sorting out negative assets by Lean IP Management, the overall value of the patent portfolio is increased and managing of remaining IP rights can be conducted more efficiently.

\section{References}

[1] Shah, R. and Ward, P.T. (2007) Defining and Developing Measures of Lean Production. Journal of Operations Management, 25, 785-805. https://doi.org/10.1016/j.jom.2007.01.019

[2] Charron, R., Harrington, H.J., Voehl, F. and Wiggin, H. (2014) The Lean Management Systems Handbook. CRC Press, Boca Raton, 95.

[3] Needles, B. and Crosson, S. (2013) Managerial Accounting. Cengage Learning, Boston, 139.

[4] Krafcik, J.F. (1988) Triumph of the Lean Production System. Sloan Management Review, 30, 41-52.

[5] Womack, J.P., Jones, D.T. and Roos, D. (1990) The Machine That Changed the World: The Story of Lean Production. Massachusetts Institute of Technology, $1-352$.

[6] Bartenbach, K. and Volz, F.-E. (2013) Arbeitnehmererfindungsgesetz ArbEG, Carl Heymanns, 952.

[7] Mittelstaedt, A. (2016) Intellectual Property Management. Springer Gabler, Berlin, 96. https://doi.org/10.1007/978-3-658-02992-0

[8] Weatherall, K.G. and Webster, E. (2010) Patent Infringement in Australia: Results from a Survey. Federal Law Review, 38, 24. https://doi.org/10.22145/flr.38.1.2

[9] Baldus, O. and Heckmann, C. (2017) Lean IP-Management-Savings Costs for IP Management Based on a Paradigm Change in Assessing Inventions. American Journal of Industrial and Business Management, 7, 760-770. https://doi.org/10.4236/ajibm.2017.76054

[10] Gassmann, O. and Bader, M.A. (2016) Patentmanagement: Innovationen erfolgreich nutzen und schützen. Springer Verlag, Berlin, 59.

[11] Ensthaler, J. and Strübbe, K. (2006) Patentbewertung-Ein Praxisleitfaden zum Patentmanagement. Springer Verlag, Berlin, 113.

[12] Grünewald, T. and Wurzer, A.J. (2012) Monetäre Patentbewertung nach DIN 77100. Beuth Verlag, 81.

[13] Baldus, O. and Heckmann, C. (2016) Increasing Profits by Strategic Patenting-A Change of Perspective from Bottom-Up to Top-Down. American Journal of Industrial and Business Management, 6, 958-966. 
https://doi.org/10.4236/ajibm.2016.69093

[14] Baldus, O. and Heckmann, C. (2011) Horizontal Patents, Commercial Benefit, and Sophisticated Patent Strategies. Journal of Intellectual Property Law \& Practice, 6, 401-408. https://doi.org/10.1093/jiplp/jpr028

[15] Baldus, O. (2010) Patent-Based Cooperation Effects. Journal of Intellectual Property Law \& Practice, 5, 111-115. https://doi.org/10.1093/jiplp/jpp216

[16] Steger, A. (2008) Überlange Verfahrensdauer bei öffentlich-rechtlichen Streitigkeiten vor deutschen und europäischen Gerichten.: Auswirkungen, Ursachen, Duncker Humblot, 202.

[17] World Justice Project Rule of Law Index (2016) The World Justice Project, 21.

[18] Padma, T.V. (2013) Indian Court Rejects Novartis Patent. Nature. https://doi.org/10.1038/nature.2013.12717

[19] Vermeulen, F. and Sivanathan, N. (2018) 2 Zeit für eine neue Strategie. Havard Business Manager, 40. 